\title{
Joubert syndrome with hepatic defect
}

INSERM

\section{Source}

INSERM. (1999). Orphanet: an online rare disease and orphan drug data base. Joubert syndrome with hepatic defect. ORPHA:1454

Joubert syndrome with hepatic defect is a very rare subtype of Joubert syndrome and related disorders (JSRD, see this term) characterized by the neurological features of JS associated with congenital hepatic fibrosis (CHF). 